\title{
A novel luminometer for rapid antimicrobial susceptibility tests on gram-positive cocci by ATP bioluminescence
}

\author{
P. F. WHEAT, R. C. SPENCER and J. G. M. HASTINGS*
}

Department of Bacteriology, Royal Hallamshire Hospital, Glossop Road, Sheffield S10 2JF and "Department of Medical Microbiology, University of Sheffield Medical School, Beech Hill Road, Sheffield S10 2RX

\begin{abstract}
Summary. The susceptibility of 130 clinical isolates of gram-positive cocci to a wide range of antimicrobial agents was assessed by ATP bioluminescence in a 4-h test. ATP assays were performed on a novel luminometer, the Amerlite Analyser, which measures luminescence from microtitration trays. For most organisms tested, there was good correlation $(>90 \%)$ with conventional MIC values estimated on $18-\mathrm{h}$ cultures. However, a problem was found with detection of penicillin resistance in Staphylococcus aureus by the ATP method, $13 \%$ of strains showing major disagreement. Methicillin resistance of $S$. aureus was shown reliably for most strains (94\%) by ATP assay, provided they were incubated at $30^{\circ} \mathrm{C}$. The Amerlite Analyser offers the potential for the development of a semi-automated antimicrobial susceptibility test, with a significant reduction in reagent costs when compared with previously described bioluminescence protocols.
\end{abstract}

\section{Introduction}

The firefly (luciferin-luciferase) assay of adenosine triphosphate (ATP) as a rapid method for determining antimicrobial susceptibility was first described from the USA National Aeronautics and Space Administration (Gutekunst, 1976) and from Sweden (Hojer et al., 1976). Commercial development has been slow, because of lack of suitable instruments and protocols and the prohibitive cost of reagents (Hastings, 1987). We described a protocol for testing Enterobacteriaceae by ATP bioluminescence (Hastings et al., 1987; Wheat et al., 1988). In the present study a novel luminometer (Amerlite Analyser; Amersham International, Little Chalfont, Buckinghamshire HP7 9NA), has been used for clinical isolates of gram-positive cocci.

\section{Materials and methods}

\section{Bacteria}

We examined 130 clinical isolates of gram-positive cocci, of which 67 were Staphylococcus aureus, 20 were coagulase-negative staphylococci (CNS), and 43 were

Received 29 July 1988; revised version accepted 28 Feb. 1989. enterococci. Of the $S$. aureus isolates, 36 (kindly supplied by Dr R. George, Central Public Health Laboratory, Colindale, London) were methicillin resistant (MRSA). The CNS isolates were mainly $S$. epidermidis (8), $S$. haemolyticus (5) or $S$. hominis (5), according to identification by API Staph (API Laboratory Products, Grafton Way, Basingstoke, Hampshire). The enterococci were identified as either Enterococcus faecalis (32) or E. faecium (11) by API 20 Strep.

\section{Antimicrobial agents}

These were obtained as pure powders of stated potency and stored at $4^{\circ} \mathrm{C}$ : fusidic acid (Leo), gentamicin (Rousell), methicillin (Beecham), penicillin (Glaxo), teicoplanin (Merrell-Dow), vancomycin (Eli-Lilly), ampicillin (Beecham).

\section{Determination of minimum inhibitory concentrations} (MICs)

Standard solutions of each antimicrobial agent were prepared in sterile distilled water for use on the same day. The MIC (lowest concentration that inhibited visible growth) was determined on Isosensitest Agar (Oxoid) containing two-fold dilutions of antimicrobial agent. Bacterial inocula of $10^{7}-10^{8} \mathrm{cfu} / \mathrm{ml}$ were transferred to the agar plates with a multipoint inoculator (Denley Instruments) and incubated for $18 \mathrm{~h}$ at $37^{\circ} \mathrm{C}$, and also at $30^{\circ} \mathrm{C}$ for methicillin. 


\section{Susceptibility testing by ATP bioluminescence}

Inoculum. Three colonies of the test organism from an overnight culture on Columbia blood agar were inoculated into $1 \mathrm{ml}$ of Hartley's Digest Broth (Oxoid) containing glucose $0.1 \%$, and incubated at $37^{\circ} \mathrm{C}$ in a reciprocating water-bath. After $1 \mathrm{~h}$, the density of cultures was adjusted to McFarland standard 2 , and $0.1 \mathrm{ml}$ was inoculated into $2 \mathrm{ml}$ of Isosensitest Broth (Oxoid) with or without antimicrobial agent. This represented an initial inoculum of $10^{6}-10^{7} \mathrm{cfu} / \mathrm{ml}$. The cultures were incubated for a further $3 \mathrm{~h}$ at $37^{\circ} \mathrm{C}$. With methicillin, cultures were incubated also at $30^{\circ} \mathrm{C}$. Final concentrations (breakpoints) were ampicillin $2 \mathrm{mg} / \mathrm{L}$, fusidic acid $0.5 \mathrm{mg} / \mathrm{L}$, gentamicin $2 \mathrm{mg} / \mathrm{L}$, methicillin $5 \mathrm{mg} / \mathrm{L}$, penicillin $0.125 \mathrm{mg} / \mathrm{L}$, teicoplanin $10 \mathrm{mg} / \mathrm{L}$ and vancomycin $10 \mathrm{mg} / \mathrm{L}$ (Pease et al., 1988).

Assay of bacterial ATP. A 200- $\mu$ l sample of the culture was mixed with an equal volume of extraction reagent consisting of trichloroacetic acid $2.5 \%$ and $4 \mathrm{mM}$ ethylene diamine tetra-acetic acid (EDTA); after $2 \mathrm{~min}, 20 \mu \mathrm{l}$ of this extract was added to $200 \mu \mathrm{l}$ of buffer (Tris-EDTA) and $20 \mu \mathrm{l}$ of ATP Monitoring Reagent (luciferaseluciferin; LKB Wallac) in a well of a microtitration tray. Light emission was measured in the Amerlite analyser. ATP-bioluminescence was expressed as a percentage:

luminescence from broth with antimicrobial agent luminescence from control broth
From our previous experience of this assay, we categorised the results empirically as sensitive $(<41 \%)$, intermediate $(41-49 \%)$ or resistant $(>49 \%)$.

\section{Analysis of ATP and MIC susceptibility results}

ATP assays were compared with MIC values by error boxes (fig. 1), based on the method of Metzler and DeHaan (1974). Strains in boxes A and B were considered as showing agreement, strains in boxes $\mathrm{C}$ and $\mathrm{D}$ as showing major disagreement, and strains with $41-49 \%$ bioluminescence as showing minor disagreement. Strains whose MIC did not differ by more than one dilution from the chosen breakpoint concentration in the ATP method were classified as showing agreement; however, these were infrequent except with methicillin at $37^{\circ} \mathrm{C}$ (fig. 2).

\section{Results}

\section{Staphylococci}

The correlation between MIC and ATP-bioluminescence is summarised in table $I$. The greatest problem was with penicillin: of 71 strains with MICs $>0.5 \mathrm{mg} / \mathrm{L}, 9(13 \%)$ were sensitive by the ATP assay and, of these, 8 were methicillinsensitive isolates of $S$. aureus. Repetition of the

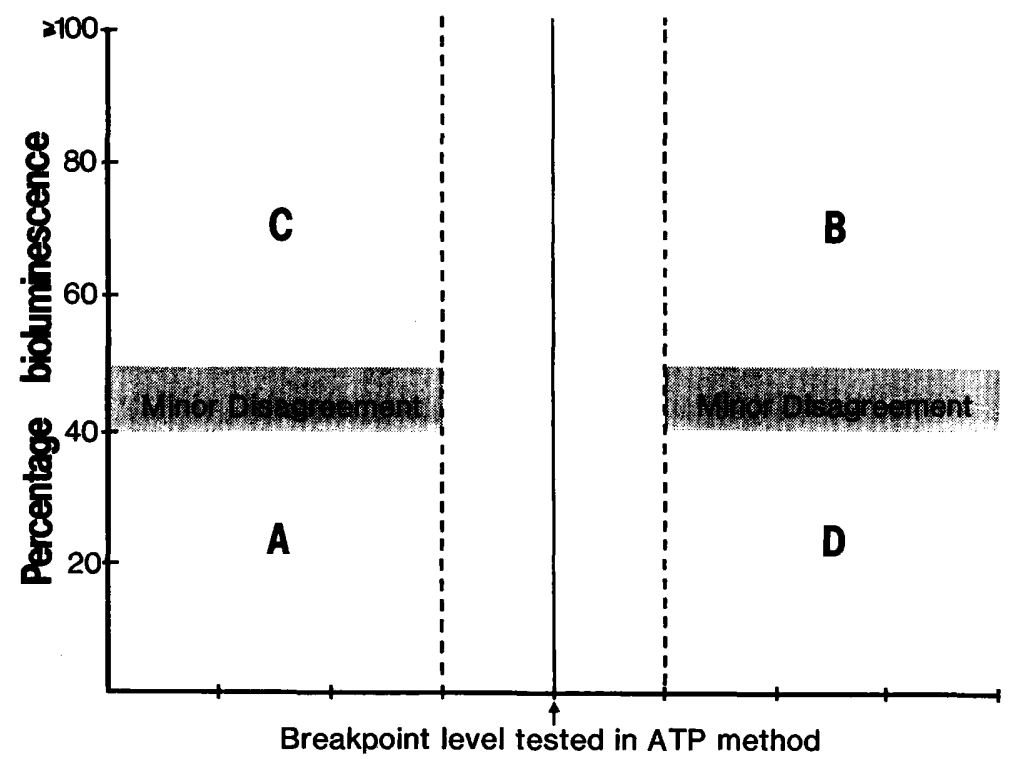

\section{Minimum inhibitory concentration $\mathrm{mg} / \mathrm{L}$}

( two-fold dilutions )

Fig. 1. Comparison of ATP-bioluminescence results and MIC values by error-box analyses. Boxes A and B indicate agreement, boxes $\mathrm{C}$ and $\mathrm{D}$ major disagreement. 

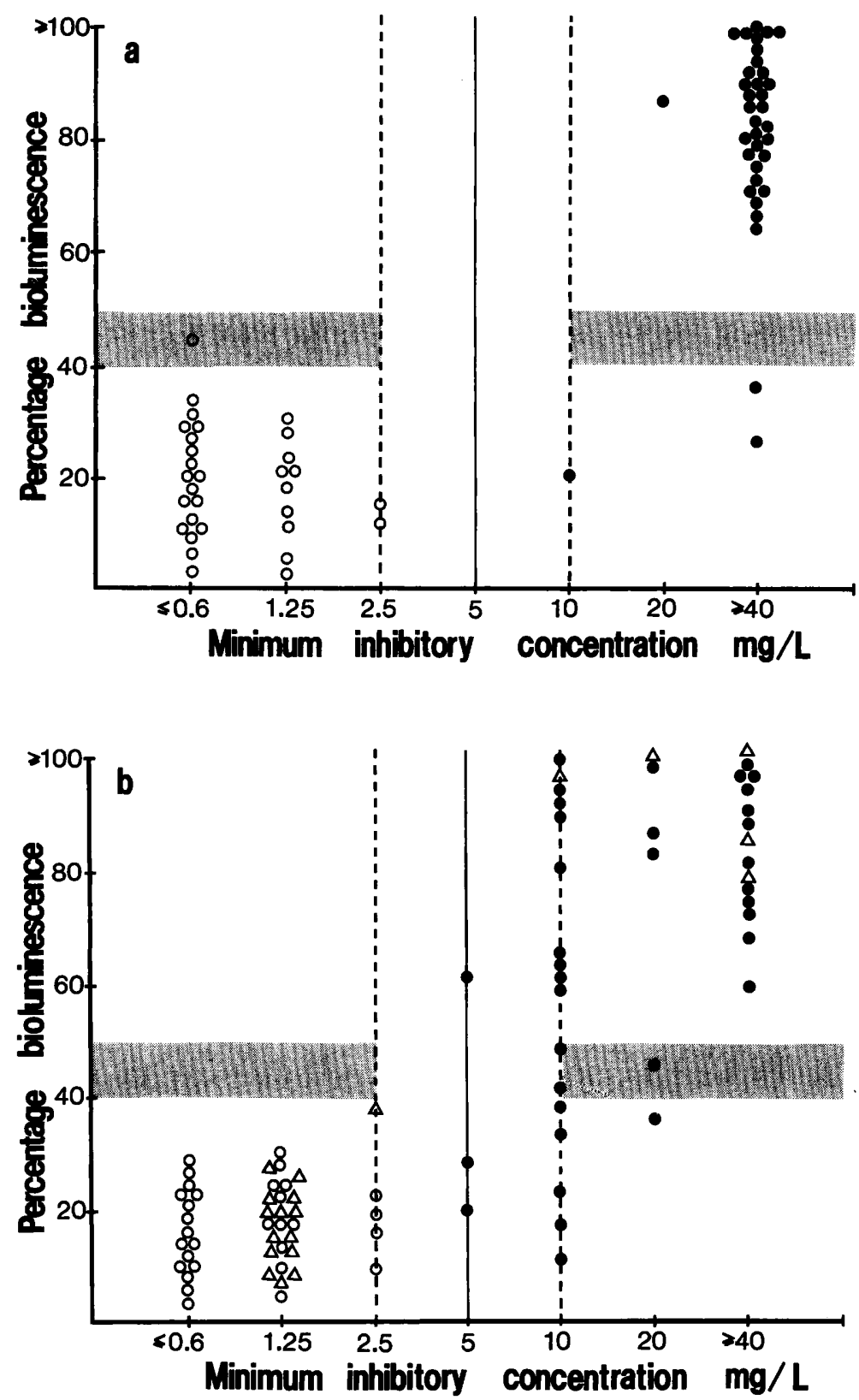

Fig. 2. Error-box analyses comparing 18 -h MIC values with ATP-bioluminescence results after incubation for $3 \mathrm{~h}$ in the presence of methicillin at a $30^{\circ} \mathrm{C}$, b $37^{\circ} \mathrm{C}$ : methicillin-resistant $S$. aureus; $\bigcirc$ methicillin-sensitive $S$. aureus; $\triangle$ coagulase-negative staphylococci.

ATP assay confirmed consistent failure to detect about $10-15 \%$ of penicillin-resistant staphylococci.

With gentamicin and fusidic acid, major disagreements were $5 \%$ and $10 \%$ respectively. However, these figures represent only single strains of CNS which were resistant by MIC; on initial testing by the ATP method they were sensitive, but on repetition they were resistant, and the original results were presumed to have been caused by manipulative errors.

Staphylococci were tested against methicillin at $30^{\circ} \mathrm{C}$ and $37^{\circ} \mathrm{C}$ by both methods (fig. 2). Predictably, MICs at $37^{\circ} \mathrm{C}$ showed wide variation with the 36 reference strains of MRSA which were said to have MICs $>40 \mathrm{mg} / \mathrm{L}$; more than half of these showed $\mathrm{MICs} \leqslant 10 \mathrm{mg} / \mathrm{L}$. In contrast, at $30^{\circ} \mathrm{C}, 34$ of the 36 
strains showed MICs $\geqslant 40 \mathrm{mg} / \mathrm{L}$. Bioluminescence results showed a similar pattern; at $37^{\circ} \mathrm{C}, 25 \%$ of MRSA strains were sensitive, compared with only three strains at $30^{\circ} \mathrm{C}$, and one of these consistently had an MIC of $10 \mathrm{mg} / \mathrm{L}$ in our hands. All methicillin-sensitive strains had low MICs and were sensitive by the bioluminescence assay at both temperatures. The CNS strains gave satisfactory results at $37^{\circ} \mathrm{C}$, but were not tested at $30^{\circ} \mathrm{C}$ because of poor growth.

\section{Enterococci}

Agreement between MIC and ATP results was good with the enterococci (table II). However, all 43 strains were sensitive to vancomycin and teicoplanin, with $\mathrm{MIC}_{90}$ values of $5 \mathrm{mg} / \mathrm{L}$ and $0.6 \mathrm{mg} / \mathrm{L}$ respectively.

\section{Discussion}

Antibiotic susceptibility results by 4 -h ATPbioluminescence assay correlated well with overnight MIC values for staphylococci tested with fusidic acid, gentamicin, vancomycin and teicoplanin, and for enterococci with ampicillin, teicoplanin and vancomycin.

However, there was a significant number of falsesensitive results by the ATP method for $S$. aureus strains with penicillin, and these false results were reproducible. A similar problem with a rapid test was encountered by Schoenknecht et al. (1980) in the Autobac system. They suggested that the discrepancies may result from staphylococci pro- ducing only low levels of $\beta$-lactamase, the organisms being destroyed before sufficient enzyme was available. Rapid estimation of $\beta$-lactamase production might avoid this problem (Sykes, 1978).

Tests for susceptibility of staphylococci to methicillin also presented problems. At $37^{\circ} \mathrm{C}$, MICs for the MRSA strains varied widely, as did the results with ATP assay; and correlation between the two methods was poor. It is now recognised that the results are influenced by a resistant sub-population which grows poorly at $37^{\circ} \mathrm{C}$ (McDougall and Thornsberry, 1984). The detection of MRSA is therefore a problem in rapid methods which rely on early detection of bacterial growth; and this was not resolved by the use of sodium chloride $5 \%$ or by incubation at $30-32^{\circ} \mathrm{C}$ (Boyce et al., 1982; Putland and Guinness, 1985). Cleary and Maurer (1978) suggested that isolates which were multi-resistant by the Autobac system should be retested by an accepted procedure. However, with ATP-bioluminescence, we have discriminated between methicillin-sensitive and -resistant strains of $S$. aureus after $3 \mathrm{~h}$ at $30^{\circ} \mathrm{C}$, and we found only $6 \%$ major disagreement with MIC results (table I). CNS strains grew poorly at $30^{\circ} \mathrm{C}$ but methicillin resistance of these organisms was detected reliably at $37^{\circ} \mathrm{C}$ (fig. $2 \mathrm{~b}$ ).

Several strains which were sensitive, intermediate or resistant by MIC and ATP methods were retested twice (data not shown); the ATP assays were as reproducible as the MICs.

Rapid tests on $S$. aureus by bioluminescence methods have been described previously. McWalter (1984), with a method similar to ours, tested 100 isolates with methicillin (at $30^{\circ} \mathrm{C}$ ), gentamicin,

Table I. Summary of error-box analyses for the comparison of MIC and ATP-bioluminescence assays of the antibiotic sensitivities of 87 strains of Staphylococcus

\begin{tabular}{|c|c|c|c|c|c|c|c|c|}
\hline \multirow{3}{*}{$\begin{array}{l}\text { Antimicrobial } \\
\text { agent }\end{array}$} & \multirow{3}{*}{$\begin{array}{c}\text { ATP } \\
\text { breakpoint } \\
(\mathrm{mg} / \mathrm{L})\end{array}$} & \multirow{3}{*}{$\begin{array}{l}\text { Number of strains } \\
\text { resistant by MIC } \\
\text { assay }\end{array}$} & \multicolumn{6}{|c|}{ Percentage of strains showing } \\
\hline & & & \multicolumn{2}{|c|}{ agreement } & \multicolumn{2}{|c|}{$\begin{array}{c}\text { minor } \\
\text { disagreement }\end{array}$} & \multicolumn{2}{|c|}{$\begin{array}{c}\text { major } \\
\text { disagreement }\end{array}$} \\
\hline & & & $\mathbf{S}$ & $\mathbf{R}$ & $\mathbf{S}$ & $\mathbf{R}$ & $\mathbf{S}$ & $\mathbf{R}$ \\
\hline Fusidic Acid & 0.5 & 10 & 97 & 90 & 3 & 0 & 0 & 10 \\
\hline Methicillin $30^{\circ} \mathrm{C}^{*}$ & 5 & 36 & 97 & 94 & 3 & 0 & 0 & 6 \\
\hline Methicillin $37^{\circ} \mathrm{C} \dagger$ & 5 & 5 & 100 & 100 & 0 & 0 & 0 & 0 \\
\hline Gentamicin & 2 & 20 & 97 & 95 & 3 & 0 & 0 & 5 \\
\hline Penicillin & $0 \cdot 125$ & 71 & 100 & 87 & 0 & 0 & 0 & 13 \\
\hline Vancomycin & 10 & 0 & 100 & - & 0 & - & 0 & - \\
\hline Teicoplanin & 10 & 0 & 100 & - & 0 & - & 0 & - \\
\hline
\end{tabular}

$\mathrm{S}=$ sensitive, $\mathrm{R}=$ resistant, by MIC assay.

* 67 strains of $S$. aureus (31 methicillin-sensitive, 36 -resistant, by MIC assay).

+20 strains of coagulase-negative staphylococci. 
Table II. Summary of error-box analyses for the comparison of MIC and ATP-bioluminescence assays of the antibiotic sensitivities of 43 strains of Enterococcus

Percentage of strains showing

\begin{tabular}{|c|c|c|c|c|c|c|c|c|}
\hline \multirow{2}{*}{$\begin{array}{c}\text { Antimicrobial } \\
\text { agent }\end{array}$} & \multirow{2}{*}{$\begin{array}{c}\text { ATP } \\
\text { breakpoint } \\
(\mathrm{mg} / \mathrm{L})\end{array}$} & \multirow{2}{*}{$\begin{array}{l}\text { Number of strains } \\
\text { resistant by MIC } \\
\text { assay }\end{array}$} & \multicolumn{2}{|c|}{ agreement } & \multicolumn{2}{|c|}{$\begin{array}{c}\text { minor } \\
\text { disagreement }\end{array}$} & \multicolumn{2}{|c|}{$\begin{array}{c}\text { major } \\
\text { disagreement }\end{array}$} \\
\hline & & & $\mathrm{S}$ & $\mathbf{R}$ & $\mathrm{S}$ & $\mathrm{R}$ & $\mathrm{S}$ & $\mathbf{R}$ \\
\hline Ampicillin & 2 & 11 & 100 & 100 & 0 & - & 0 & - \\
\hline Vancomycin & 10 & 0 & 100 & - & 0 & - & 0 & - \\
\hline Teicoplanin & 10 & 0 & 100 & - & 0 & - & 0 & - \\
\hline
\end{tabular}

$\mathrm{S}=$ sensitive, $\mathrm{R}=$ resistant, by MIC assay.

clindamycin, erythromycin and fusidic acid, and found good correlation with standard disk diffusion results and MIC values. Barton (1985) used a novel approach in assaying extracellular release from staphylococci after incubation with methicillin and treatment with lysostaphin; although only 29 strains were examined, the results were similar to those with conventional tests. Unfortunately, this method is applicable only to $S$. aureus, because other staphylococci may not be susceptible to lysostaphin (Barton, 1985). These studies and earlier reports on bioluminescence have relied on single-chamber luminometers (Picciolo and Chappelle, 1977; Thore et al., 1977). Such methods are labour-intensive, and the luciferin-luciferase reagent costs $£ 0.3-0.5$ per test. The Amerlite analyser is a sensitive microtitration-plate reader, designed primarily for luminescence immunoassays. Its application for ATP bioluminescence was first reported by Oxley et al. (1987) and Wheat et al . (1987). The microtitration technique has advantages: multi-channel dispensers can be used for transfers and additions, and the small volumes reduce the cost per test to less than $£ 0.05$.

Although our technique is simpler than previous ATP methods, it still requires improvement. We are now developing a procedure in which all steps are performed in microtitration trays; also, the Amerlite Analyser needs a substantial database and facilities for storage and retrieval of results in epidemiological analysis of antimicrobial patterns.

\section{REFERENCES}

Barton A P 1985 A rapid bioluminescent method for the detection of methicillin-resistant Staphylococcus aureus. Journal of Antimicrobial Chemotherapy 15: 61-67.

Boyce J M, White R L, Bonner M C, Lockwood W R 1982 Reliability of the MS-2 system in detecting methicillinresistant Staphylococcus aureus. Journal of Clinical Microbiology 15 : 220-225.

Cleary T J, Maurer D 1978 Methicillin-resistant Staphylococcus aureus susceptibility testing by an automated system, Autobac-1. Antimicrobial Agents and Chemotherapy 13: 837841 .

Gutekunst R R 1976 Rapid procedures under development and evaluation: bioluminescence and impedance measurement. In: Bondi A D et al. (eds) The clinical laboratory as an aid in chemotherapy of infectious disease. Williams and Wilkins, Baltimore, pp 85-100.

Hastings J G M 1987 Luminescence in clinical microbiology. In: Scholmerich J (ed) Bioluminescence and chemiluminescence. Proceedings of the 4th International Symposium. John Wiley, Chichester, pp 453-461.

Hastings J G M, Wheat P F, Oxley K M, Spencer R C 1987 ATP bioluminescence susceptibility testing using a novel

luminometer. 27th Interscience Conference on Antimicrobial Agents and Chemotherapy, New York. Abstract no. 330.

Hojer H, Nilsson L, Ansehn S, Thore A 1976 In-vitro effect of doxycyline on levels of adenosine triphosphate in bacterial cultures : possible clinical applications. Scandinavian Journal of Infectious Diseases Suppl 9: 58-61.

McDougall L K, Thornsberry C 1984 New recommendations for disk diffusion antimicrobial susceptibility tests for methicillin-resistant (heteroresistant) staphylococci. Journal of Clinical Microbiology 19: 482-488.

McWalter P W 1984 Rapid susceptibility testing of Staphylococcus aureus. In: Kricka L J (ed) Analytical applications of bioluminescence and chemiluminescence. Academic Press, London, pp 17-20.

Metzler C M, DeHaan R M 1974 Susceptibility tests of anaerobic bacteria: statistical and clinical considerations. Journal of Infectious Diseases 130: 120-130.

Oxley K M, Wheat P F, Spencer R C, Hastings J G M 1987 Kinetics of antibiotic action studied using ATP bioluminescence. In: Scholmerich J (ed) Bioluminescence and chemiluminescence. Proceedings of the 4th International Symposium. John Wiley, Chichester, pp 495-498.

Pease A A, Wheat P F, Harris D M 1988 Antimicrobial 
susceptibility testing and biochemical identification using multipoint inoculation: 5 years' experience. Medical Laboratory Sciences 45 : 28-33.

Picciolo G L, Chappelle E W 1977 Application of firefly luciferase assay for adenosine triphosphate (ATP) to antimicrobial drug sensitivity testing. NASA Technical Note D-8439.

Putland R A, Guinness M D G 1985 Autobac susceptibility testing of methicillin-resistant Staphylococcus aureus isolated in an Australian hospital. Journal of Clinical Microbiology 21 : 822-827.

Schoenknecht F D, Washington J A, Gavan T L, Thornsberry C 1980 Rapid determination of minimum inhibitory concentrations of antimicrobial agents by the Autobac method: a collaborative study. Antimicrobial Agents and Chemotherapy 17: 824-833.
Sykes R B 1978 Methods for detecting beta-lactamases. In: Reeves D S et al. Churchill Livingstone, London, pp 64-70. Thore A, Nilsson L, Hojer H, Ansehn S, Brote L 1977 Effects of ampicillin on intracellular levels of adenosine triphosphate in bacterial cultures related to antibiotic susceptibility. Acta Pathologica Microbiologica et Immunologica Scandinavica 85B: $161-166$.

Wheat P F, Oxley K M, Spencer R C, Hastings J G M 1987 Rapid antibiotic susceptibility testing by ATP bioluminescence assayed with a new luminometer. In: Scholmerich J (ed) Bioluminescence and chemiluminescence. Proceedings of the 4th International Symposium. John Wiley, Chichester, pp 499-502.

Wheat P F, Hastings J G M, Spencer R C 1988 Rapid antibiotic susceptibility tests on Enterobacteriaceae by ATP bioluminescence. Journal of Medical Microbiology 25: 95-99. 